\title{
A review of open source ventilators for COVID-19 and future
}

\section{pandemics [version 1; peer review: 2 approved, 1 approved}

\section{with reservations]}

\author{
Joshua M. Pearce (iD) 1-3 \\ ${ }^{1}$ Department of Materials Science \& Engineering and Department of Electrical \& Computer Engineering, Michigan Technological \\ University, Houghton, MI, 49931, USA \\ 2Équipe de Recherche sur les Processus Innovatifs (ERPI), Université de Lorraine, Nancy, France \\ ${ }^{3}$ School of Electrical Engineering, Aalto University, Helsinki, Finland
}

V1 First published: 30 Mar 2020, 9:218

https://doi.org/10.12688/f1000research.22942.1

Latest published: 30 Apr 2020, 9:218

https://doi.org/10.12688/f1000research.22942.2

\section{Abstract}

Coronavirus Disease 2019 (COVID-19) threatens to overwhelm our medical infrastructure at the regional level causing spikes in mortality rates because of shortages of critical equipment, like ventilators. Fortunately, with the recent development and widespread deployment of small-scale manufacturing technologies like RepRapclass 3-D printers and open source microcontrollers, mass distributed manufacturing of ventilators has the potential to overcome medical supply shortages. In this study, after providing a background on ventilators, the academic literature is reviewed to find the existing and already openly-published, vetted designs for ventilators systems. These articles are analyzed to determine if the designs are open source both in spirit (license) as well as practical details (e.g. possessing accessible design source files, bill of materials, assembly instructions, wiring diagrams, firmware and software as well as operation and calibration instructions). Next, the existing Internet and gray literature are reviewed for open source ventilator projects and designs. The results of this review found that the tested and peerreviewed systems lacked complete documentation and the open systems that were documented were either at the very early stages of design (sometimes without even a prototype) and were essentially only basically tested (if at all). With the considerably larger motivation of an ongoing pandemic, it is assumed these projects will garner greater attention and resources to make significant progress to reach a functional and easily-replicated system. There is a large amount of future work needed to move open source ventilators up to the level considered scientific-grade equipment, and even further work needed to reach medical-grade hardware. Future work is needed to achieve the potential of this approach by developing policies, updating regulations, and securing funding mechanisms for the development

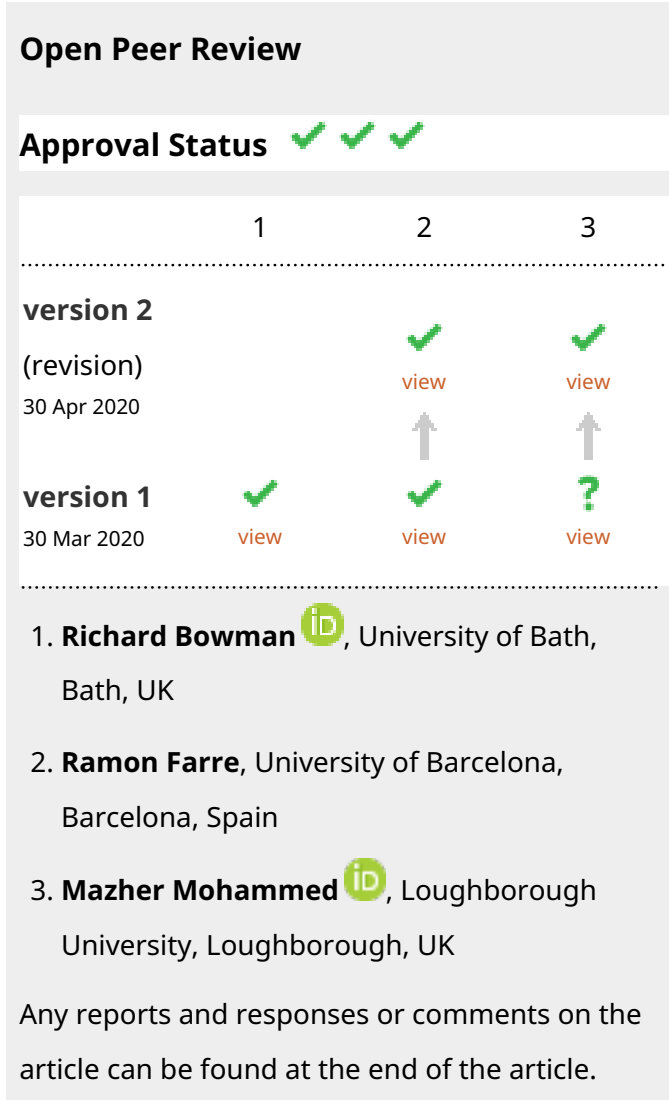


and testing of open source ventilators for both the current COVID19 pandemic as well as for future pandemics and for everyday use in lowresource settings.

\section{Keywords}

ventilator, pandemic, ventilation, influenza pandemic, open source, open hardware, COVID-19, medical hardware

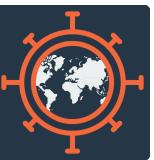

This article is included in the Emerging Diseases

and Outbreaks gateway.

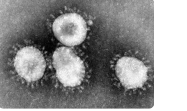

This article is included in the Coronavirus

collection.

\section{Corresponding author: Joshua M. Pearce (pearce@mtu.edu)}

Author roles: Pearce JM: Conceptualization, Formal Analysis, Funding Acquisition, Investigation, Resources, Validation, Writing Original Draft Preparation, Writing - Review \& Editing

Competing interests: No competing interests were disclosed.

Grant information: This work was supported by the Witte Endowment.

The funders had no role in study design, data collection and analysis, decision to publish, or preparation of the manuscript.

Copyright: ( $) 2020$ Pearce JM. This is an open access article distributed under the terms of the Creative Commons Attribution License, which permits unrestricted use, distribution, and reproduction in any medium, provided the original work is properly cited.

How to cite this article: Pearce JM. A review of open source ventilators for COVID-19 and future pandemics [version 1; peer review: $\mathbf{2}$ approved, 1 approved with reservations] F1000Research 2020, 9:218 https://doi.org/10.12688/f1000research.22942.1

First published: 30 Mar 2020, 9:218 https://doi.org/10.12688/f1000research.22942.1 


\section{Introduction}

Coronavirus disease 2019 (COVID-19), caused by a novel coronavirus (SARS-CoV-2), is in part so dangerous because it threatens to overwhelm our medical infrastructure at the regional level, causing spikes in mortality rates ${ }^{1-4}$. Within the medical infrastructure, there are critical technologies that are generally available, but simply do not exist in a high enough density to handle the excessive volume of patients associated with pandemics ${ }^{5}$. Thus, people die unnecessarily throughout the world because of a combination of COVID-19 infections and the lack of access to some of these technologies ${ }^{6}$. Ventilators are an example of technologies that are currently in critical short supply ${ }^{7,8}$. Mechanical ventilators are essential for treating both influenza and COVID-19 patients in severe acute respiratory failure ${ }^{9,10}$. Past studies have shown that intensive care units (ICUs) will not have sufficient resources to treat all patients requiring ventilator support during a massive pandemic ${ }^{11-13}$, and ethically challenging triage ${ }^{14,15}$ would need to be used to decrease mortality over firstcome first-served basis for ventilator allocation among patients. Some work has shown promise for using a single ventilator to support multiple patients during a disaster surge ${ }^{16-18}$. In addition, it has already been shown that 3-D printed manifolds can assist with rapidly deploying this solution and there are open source designs ${ }^{19}$. This is not necessarily straightforward ${ }^{20}$. Although some countries, like the United States, have stockpiles of ventilators $^{21}$, there is consensus that there is not enough supply for serious pandemics ${ }^{22-25}$ and that rationing would be needed ${ }^{26}$. The current medical system relies exclusively on specialized, proprietary, mass-manufactured ventilators from a small selection of suppliers. This supply model clearly fails when there is a sudden surge in demand for a relatively low-volume specialty product such as ventilators in a pandemic as analyzed here. The vast majority of medical equipment is heavily patented by a few specialty medical firms that sell small volumes because during 'normal' times, a medium-sized hospital only needs a handful. These firms have historically aggressively protected their intellectual monopolies ${ }^{27-28}$ to the detriment of human lives (for a recent example, consider the fact that a manufacturer threatened to sue a maker for 3-D printing life-saving valves in Italy for patent infringement ${ }^{29}$. In addition, non-practicing entities continue to attempt to actively prevent medical treatments from being deployed, even during the current COVID-19 pandemic ${ }^{30}$. Putting aside the absurdity of patenting and then obstructing others from using obvious inventions in normal times ${ }^{31-33}$, in the wake of a pandemic where millions of lives are at stake, it is intuitively obvious that this type of greed is no longer acceptable.

Fortunately, with the recent development and widespread deployment of open source small-scale manufacturing technologies ${ }^{34,35}$, there is now another way - mass distributed manufacturing ${ }^{36-39}$. In this new model, designs are developed and then shared with open source licenses freely on the Internet so that others can simply download and replicate the design on their own equipment, even at the household scale ${ }^{40}$. There has been tremendous and ongoing success of open source scientific hardware proliferation $^{41-46}$, where lower-cost and superior-functioning custom equipment as compared to proprietary scientific tools ${ }^{47-50}$. Based on such scientific hardware results, there appears to be a significant opportunity to apply open source design principles $^{51}$ and mass-scale collaborative distributed manufacturing technologies to make medical equipment ${ }^{52-55}$. In the current situation, this would at least partially overcome medical supply shortages ${ }^{56-61}$ in general, and specifically for ventilators.

Of these enabling technologies, the most advanced is the fused filament fabrication (FFF)-class of desktop 3-D printers that have spawned from the self-replicating rapid prototyper (RepRap) project ${ }^{62-64}$. With the distributed manufacturing model, designs are downloaded even in remote areas and are manufactured on demand as needed ${ }^{65}$ from readily available (and possibly recycled ${ }^{66-78}$ ) materials. These $3-\mathrm{D}$ printers are, in general, not particularly fast when making products, but with tens of thousands of 3-D printers already strategically deployed all over the world ${ }^{79}$, they have the capacity to fabricate an incredibly diverse and large range of products (growing exponentially) ${ }^{80}$, which have already been shared with open source design licenses. Here, the potential will be analyzed for hardware that can be as-much-as-possible digitally manufactured using accessible low-cost fabrication tools like RepRap-class 3-D printers and then readily constructed from widely accessible materials and simple tools (e.g. DIY hardware store sourced along with Arduino-class microcontrollers).

In this study, after providing a background on ventilators, the academic literature will be reviewed to find the existing and already openly published vetted designs for ventilator systems. These articles will be analyzed to determine if the designs are open source both in spirit (license) ${ }^{81}$ as well as required practical details, which include possessing the design source files (e.g. CAD) as well as production files (e.g. STL), PCB layouts and other electronics design files, bill of materials (BOM), list of tools required, wiring diagrams, firmware and software, as well as instructions for the assembly, calibration and operation. Next, the existing Internet and gray literature will be reviewed for open source ventilator projects and designs. Lastly, as this is a rapidly evolving area, future work will be described to enable wide-spread mass distributed manufacturing of open source ventilators to fight against the current COVID19 pandemic as well as for future pandemics and to provide the devices to low-resource regions of the world that are underserved even in normal times.

\section{Analysis of literature}

Oxygen therapy coupled with mechanical ventilation is meant to support patients so that an adequate oxygen saturation $(>88 \%)$ in arterial blood is maintained ${ }^{82}$. The mechanical repository cycle has four parts: 1) inspiration, where the exhalation valve of the ventilator is closed and the ventilator uses pressured air to cause gas to flow into the lungs; 2) cycling, where changeover from inspiration to expiration occurs; 3) expiration, where the main ventilatory flow is interrupted and the exhalation valve opened to allow gas to escape from the lungs, and 4) triggering, where the changeover from expiration to inspiration occurs. According to Andreoli et $a l^{82}$, mechanical ventilators are classified on what factor terminates inspiratory flow, as follows: 1) pressure-cycled ventilators terminate flow when preset pressures 
are reached in airways; 2) volume-cycled ventilators provide a set volume of gas to the patient over a range of pressures (but a maximum pressure is set to avoid damage to the patient's lungs during delivery of the set tidal volume); 3) time-cycled ventilators set tidal volume by setting the inspiratory time and flow rate; and 4) flow cycled ventilators, where the inspiratory flow is terminated when the inspiratory flow rate drops below a specific level. The most common commercial modes of mechanical ventilation both provide a specified number of breaths per minute (BPM) and are 1) synchronized intermittent mandatory ventilation (SIMV) where patients can take additional breadths over the set rate and 2) assist control (AC) that uses triggering so that if the patient makes an effort to breathe, it helps them, and if not, it maintains the set rate. These modes can be used alone or in concert with 1) continuous positive airway pressure (CPAP), which uses a high-pressure reservoir and constant flow of gas that exceeds the patient's needs; 2) positive end-expiratory pressure (PEEP), which increases the residual reserve capacity and allows for many alveoli and small airways to remain open that would otherwise close off; or 3) pressure support ventilation (PSV), which adjusts the pressure on the fly as the patient breathes to maintain a preset inspiratory pressure. For those designing open source ventilators using any of those modes and methods, there is a good base of established literature to draw upon. The classic background is available in Hess, et al.'s 1996. Essentials of mechanical ventilation, ${ }^{83}$ Tobin's 2010 Principles and practice of mechanical ventilation ${ }^{84}$, and Owens' 2018. The Ventilator Book ${ }^{85}$. In addition, Chapter 4 in the openly accessibly book Equipment in Anaesthesia and Critical Care: A complete guide for the FRCA, provides a good starting point to help makers understand existing designs and terminology for ventilators ${ }^{86}$. Texts area available for the use of a ventilator for the standard of care of patients with acute respiratory distress syndrome (ARDS) $)^{87}$, ventilator management for the $\mathrm{NIH}^{88}$, and the practical use of oxygen for patients ${ }^{89}$. A 2017 state-of-the-art review of mechanical ventilation is presented by Pham et al. ${ }^{90}$ It provides basic schematic diagrams for all of the main classes of commercialized ventilators and reviews their pros and cons.

\section{Existing peer-reviewed literature}

The peer-reviewed literature itself is currently limited, but there has been some research on low-cost ventilation, even if the source is not available. First, a field portable ventilator system for domestic and military emergency medical response has been conceptually designed, but does not include enough information to construct it (e.g. the software was written in assembly language and not shared $)^{91}$. This article does contain design considerations that may be useful for open source designers.

A new, compact and low-cost mask respirator concept has been developed and prototyped successfully ${ }^{92}$. The blower unit was able to provide adequate ventilation to the test lungs. In addition, the integrated sensor for airway pressure was able to detect airway occlusion and leakages. It is a relatively low-power device and could be operated wirelessly with batteries. It provides a cross-sectional view of the blower unit and some details, but again, not enough to be considered full open hardware or to be easily replicated. It should be noted, however, that many of the components are within RepRap-class 3-D printing capabilities.

In addition, research has been undertaken on a pre-stage public access ventilator (PAV $)^{93}$. The PAV is made up of several low cost technologies including a self-designed turbine and a range of sensors for differential pressure, flow, $\mathrm{F}_{\mathrm{i}} \mathrm{O}_{2}, \mathrm{~F}_{\mathrm{i}} \mathrm{CO}_{2}$ and threeaxis acceleration measurements. The PAV was tested under three conditions to show that it was adequate for an automatic emergency system: 1) pressure-controlled ventilation (PCV), 2) PCV with controlled leakage and 3) PCV with simulated airway occlusion. The PAV was tested for and showed effective ventilation for tidal volume, breathing frequency and inspiratory pressure. Similarly, there has been a proposal to replace artificial manual breathing unit (AMBU) bags with electric blowers to act as emergency ventilators ${ }^{94}$

In contrast, another approach is to build a low-cost ventilator utilizing an AMBU bag that is not based on constant blower use $^{95}$. The study by Mukaram Shahid showed the AMBU setup was able to perform all the functions of a conventional commercial ventilator for a far lower cost $(<\$ 100 \mathrm{US}$ excluding labor). The automated AMBU device was able to adjust the breathing rate and the volume of the air, which is comparable to older ventilators. However, it was also able to regulate the inspiration to expiration ratio and PEEP rate. Shahid's system comes with two modes: 1) mandatory ventilation (as in older models) and 2) assisted ventilation (as with most current systems). Thus, the medical personnel can choose to use either the built-in triggering mechanism (assist boosted mode), which alters the respiration pattern once it detects a change in air pressure, or set a time interval for the respiration pattern. The article contains pictures, an electric schematic, a control loop diagram, and very basic results. Again, this can be used as starting point, but there is not enough shared to replicate in the open hardware fashion.

Next, a low-cost ( $\$ 420$ prototype) portable mechanical ventilator was designed and prototyped that delivers breaths by compressing a conventional bag-valve mask (BVM) with a pivoting camactuated arm pushed by an electric motor ${ }^{96}$. This eliminates the need for a person pushing on the BVM, which is generally viewed as only a short-term solution. This system uses knobs to determine the tidal volume appropriate to the patient (usually $6-8 \mathrm{~mL} / \mathrm{kg}$ of ideal body weight), adjustable BPM of 5-30, and inhalation to exhalation time ratio options of $1: 2,1: 3$ and $1: 4$ and a minimum respiratory rate ${ }^{97}$. This design is run with an open source Arduino micro-controller ${ }^{98}$ and the article provides enough details to be used as a guide for others to build a similar device, but not the full plans, code, etc. needed to qualify as an open source hardware device.

The most relevant design is a pneumatic ventilator specifically designed for pandemics, which has a low oxygen consumption ${ }^{99}$. In this study by Williams et al., they describe and test three simple, pneumatically powered, low oxygen-consumption ventilators. The three designs were tested for different lung compliances (i.e. different ventilator workloads) on the delivered 
$\mathrm{F}_{\mathrm{i}} \mathrm{O}_{2}$ and oxygen consumption. They used a commercial mechanical test lung for these tests (Vent Aid; Michigan Instruments Inc., Grand Rapids, MI, USA). The results of this study support the potential for mass distributed production of a low-cost, gas-powered, volume-controlled ventilator with a low oxygen consumption (anywhere with oxygen at 2-4 bar). The designs could alternatively be operated on hospital compressed air. The single use, self-inflating bellows system prevents cross contamination among patients. In addition, the system possessed one-way and safety overpressure valves, which could be incorporated into other designs. The designs are in part supplied including basic principle schematics, an example BOM, but falls far short of what is expected for a complete open hardware design.

There are also completely different approaches to the design of a ventilator, such as the high-frequency oscillatory ventilator ${ }^{100}$, but only basic design schematics and preliminary testing is provided. Thus, within the peer-reviewed literature, most of the quasi-appropriate ventilator devices use a standard ventilation bag that is cyclically compressed by either an electromechanic or pneumatic setup and controlled by a microcontroller. Fortunately, the most complicated part of these designs is the controls, which is made accessible by the maturation of Arduino-based microcontrollers that can actuate and sense over a wide array of accessible and already-developed technologies (e.g. code libraries are available). It should be noted that most of the lowcost options in the literature used the bag approach, but that modern commercial ventilators are generally not manufactured with bags, bellows or pistons due to performance concerns. These concerns may be overcome by the nature of a pandemic, as well as by replacing low-cost components during failure, but this does indicate failure detection is warranted and certainly preferred in an open source ventilator design.

\section{Open source ventilator designs shared on the web}

There are a number of proprietary commercial low-cost products like the Pumani bubbleCPAP for infants, D-box or One Breath Ventilators (not yet for sale), which could be used to relieve some of the demand for conventional ventilators. Rather than attempting to conduct a market review of such devices, however, because presumably hospitals facing a shortage of ventilators would already consider all commercially-available and regulated/ approved systems, this section will investigate the growing body of knowledge to help makers develop open source ventilators as well as the preliminary designs. This section was largely supported by information gathering of the rapidly evolving open source Internet communities such as Project Open Air, which is a group of "Helpful Engineers" on the platform Just One Giant Lab. They have congregated to help in the COVID-19 pandemic by developing open source solutions and of most relevance to this study, on a project specifically on the development of open source ventilators. Their documentation and information is freely available. Although just starting, as of 17 March 2020, they have over 2,500 registered volunteers and over 9,000 on their Slack team. In addition to an offset ventilator, in their first round of project proposals, they have prioritized oxygen concentrators and personal protective equipment (PPE) as their top priority projects. In addition, their future work will focus on tube connectors and building a database for local manufacturers able to produce hardware with high score in reviews. There are other teams including those organizing around the open source wiki Appropedia for an open source ventilator. Facebook has an Open Source COVID19 Medical Supplies Group. There is a long-going Pandemic Ventilator Project that hosts their designs on Instructables. The RepRap community is starting on an opensource oxygen concentrator, which can be used alone or in tandem with an open source ventilator. Hackaday has recently called for a medical hackathon to design and deploy an open source ventilator $^{101}$. Other communities are crowd-sourcing information about COVID-19 medical technologies and developing a Coronavirus Technology Handbook. Some resources for makers are appearing as basic specification provided by Botta. In addition, The Center for Safety, Simulation, and Advanced Learning Technologies (CSSALT) at the University of Florida has started an open source ventilator project based on hardware store components on the assumptions that the FDA will waive clearance for the bare-bones design if there is a massive shortage. The CSSALT system is one of the most professionally documented, with full files available for each sub-system and published engineering specifications for the ventilator that could be useful even for open hardware designers using completely different approaches. They are maintaining their documentation on GitHub. Many of the sub-modules, however, have not yet been developed, nor have a team working on them. Other projects are also using GitHub, like Jackson's Open Respirator project, but are at the very beginning stages of development as of this writing. To assist these efforts the UK government has issued guidelines.

One approach favored by both the academic literature as well as the maker community is just to use manual ventilators - BVMs/ AMBU bags. There are many commercial suppliers available and there is very preliminary documentation for open source manual ventilation for the developing world ${ }^{102,103}$. Although, in theory, purely manual ventilation could work to provide ventilation for patients over long periods, there is a real concern of both the availability of the needed man-power, as well as the continued exposure of the laborer. In addition, using a bagvalve mask may increase aerosolization of virus, and in general medical staff are not supposed to bag mask before intubation due to that risk. Many of the open source designs rely on this BVMs/AMBU bags approach where one automates the manual squeezing. It only needs an exhaust system and PEEP valve. Students at Rice University have also created an automated bagvalve mask device that fits around a normal BVM using a dual rack and pinion design with a servo motor that continuously operates (open/close) squeezing the bag a specific amount to supply air. Rice provides a full non-peer-reviewed report, that is considerably richer in details than most of the others. It offers their design strategy, a partial BOM, basic testing, the source code as well as a summary of the standards and regulations necessary to go to market. Unfortunately, in their preliminary testing, the servo motor failed after only 11 hours of service and Rice is withholding the full CAD designs and results. To overcome the limitations of both the MIT and Rice designs, a group in Ireland formed and is moving along with full open source documentation of OpenLung on GitLab. They are on their 
fifth iteration as of this writing based on the surrounding low-cost BVM/AMBU bag concept discussed above. Another project building off the MIT design is DIY Ventilators. Finally, the open hardware OxyGEN project is also using automated AMBU approach and although at the preliminary stages their 3-D and MATLAB design files are hosted openly on GitHub.

Makers are also considering other types of non-invasive ventilators (NIV) such as those based CPAP (an alternative to PEEP), which is a form of positive airway pressure ventilator that applies mild air pressure on a continuous basis. A 3-D printed CPAP fan has been designed and tested as a blower and the design files (AutoDesk Fusion 360) and STLs are freely available. Another approach is to turn a commercial CPAP machine into a ventilator currently under development on GitHub by Lee. Lee built the system around an Arduino nano and has performed very basic tests to it that show that it provides enough pressure for a ventilator used on COVID-19 patients; however, there is not nearly enough information to recommend it for medical use. In addition, there are bi-level positive airway pressure (BiPAP) machines that are commonly used at home to treat sleep apnea and lung diseases as they decrease the effort of breathing by changing the pressure for inhalation and exhalation. Homeuse BiPAPs could be used in place of hospital NIVs, but care would need to be taken because poor interfaces could generate viral aerosols ${ }^{104}$. Negative pressure ventilation (iron lung) overcomes this problem, helping lung function by pulling from the outside (there has been some development on Appropedia). It provides a full $\mathrm{BOM}$, but insufficient details for replication or complete open source documentation.

In addition, several makers have developed pandemic ventilators, such as John Strupat, some time $\operatorname{ago}^{105}$, but unfortunately, in addition to the lack of testing, the source does not appear accessible. Another approach is to use a blower, as in the Pandemic Pressure Control Ventilator being developed openly on HackaDay.Io by Frank. Other open source projects are at their beginnings, like the TogRespirator project housed on GitHub developed for a Science Hackday Dublin 2020, DIY and open source respiratory and a project to build an open source ventilator on GoFundMe.

In the review of Internet-reported ventilators, it is somewhat disappointing that many of the most promising designs do not share their source code. In fact, in some cases, little more than a picture or video are available. The newer projects do tend to be following better documentation protocols. Unfortunately, despite the many promising approaches in the maker community, the one problem that the vast majority of the current partial designs have in common is that there is not nearly enough information available about their performance to recommend them for medical use.

\section{Future work needed}

It is clear from this review of the peer-reviewed, gray and open web literature on open source ventilators, that there is considerably more work to do. The tested and peer-reviewed systems lacked complete documentation and the open systems that were documented appropriately were either at the very early stages of design (sometimes without even a prototype) and were essentially only basically tested (and some were not tested at all). With the considerably larger motivation of an ongoing pandemic, it is assumed that these projects will garner more resources and members (as is happening with the Open Air Project) to reach a critical mass to make significant progress to reach a functional and replicable system. Although the motivation of working during a pandemic on a device that may save your life is high, the access to resources, however, is far from optimal. Already, many locations throughout the world are essentially forcing citizens to shelter-in-place, which restricts access to government and university labs, as well as to makerspaces and fab labs. In addition, some areas of the world are suffering from supply disruptions and shipping challenges. This perhaps underscores the importance of developing open source hardware for disasters before the disaster strikes. Future work is needed to develop policies and funding mechanisms for such work as it appears rational to make a small investment in developing and sharing the designs for any critical hardware.

This review article uncovered other limitations to this approach. First, due to 1) potential legal issues challenging an open source ventilator design, and 2) the general lack of useful technical information in patents (the average Instructable generally has more useful information for constructing a device than a patent despite that being a requirement of obtaining a patent), patents were not included in this review. It should be noted, however, that there are currently over 277 inactive patents in addition to those that have expired covering ventilators. Researchers can obtain this list with direct links to these patents using the Michigan Tech Free Inactive Patent Search ${ }^{106}$. There may be useful information contained in those documents that could help open source ventilator designers.

Another challenge with this approach is maintaining a proper level of sterility of devices fabricated using distributed means. Specifically, for the FFF-based 3-D printing parts, it has been reported that the prints are sterile at the time of print ${ }^{107}$. If not kept in a sterile environment, however, they could quickly become biologically contaminated. One approach to deal with this is to use washing or a chemical bath. A relatively complete analysis of the chemical compatibility of commercial 3-D printed plastics is available ${ }^{108}$. If a specific polymer is needed that cannot be 3-D printed easily, it is possible to make molds in hightemperature plastics, such as polycarbonate, and then use lower temperature plastics to make disposable single use plastic parts ${ }^{109}$. Similarly, silicone molds can be made from a 3-D printed reverse mold and used in the same way ${ }^{110 .}$

Even when more mature open source ventilator designs are available and can be safely manufactured by a distributed means, another area of critical future work is validation of these designs. In the medical sciences, open source devices like syringe pumps $^{111,112}$ are already established ${ }^{113-116}$ and have been developed into sophisticated devices ${ }^{117-122}$. However, these devices are used in labs in general and not on people continually. For medical professionals to use an open source ventilator, 
they first must be convinced it will do no harm to them (or others) as well as to the patient. As COVID-19 was reported to spread via droplets, contact and natural aerosols from human-tohuman, there has been a concern that high-risk aerosolproducing procedures may put medical personnel at high risk of nosocomial infections, which is a concern for some designs reviewed here ${ }^{123}$. During the airway management, enhanced droplet/airborne PPE is needed and the study by Zuo et al. provides a list of other recommendations to overcome this challenge. There have been some developments in 3-D printing some of these PPE $^{124,125}$. Similarly, for designs that could aerosolize the virus, a negative pressure room would be necessary and future work is needed to design an open source approach to creating such rooms. Likewise, the greatest concern for untested open source ventilator designs is that they harm the lungs of the patients; there is significant literature in this area of ventilatorinduced lung injury ${ }^{126-133}$. There are, however, solutions for preventing this, like controlling the tidal volume ${ }^{134,135}$. Thus, the designers of open source ventilators must ensure that their designs have safety features to prevent ventilator-induced lung injury, as well as having basic testing of the prototypes to ensure that the designs themselves are thoroughly vetted.

Within the open source scientific equipment community, such procedures are relatively well established and have been working reasonably well through normal peer review of hardware-based articles like those published by HardwareX, the Journal of Open Hardware, and PLOS One. For medicalequipment that could be all that stands between life and death, this vetting is even more important and open calls for papers for a Special Issue on Open-Source COVID19 Medical Hardware are attempting to address this.

However, technical validation may not be enough. Medical hardware used on humans is also more complicated, as any studies involving humans needed to verify its functionality on people, need institutional review board approval and, if in regulated areas like the U.S., such a study would need an Investigational Device Exemption to allow for a non-FDA approved device to be used as part of a study. This is only a temporary approval and the full device would need actual FDA approval for legal deployment unless the laws are changed (or were temporarily suspended during a pandemic). These same regulatory roadblocks are in place in other nations, which has conventional ventilator manufacturers skeptical that even conventional manufacturers of other products (e.g. vacuum cleaner and automobile manufacturers are doing this now in the UK) could switch over to produce ventilators ${ }^{136}$. Clearly, this process is a problem during a pandemic. Both for the current situation and during potential future situations, there is a need to limit liability on the part of the designers, makers and users of such open source medical hardware ${ }^{137}$. Substantial future work is needed in this area. Interestingly, this gives less-developed countries with a less-formalized regulation and litigation infrastructures a distinct advantage for protecting their citizens during a pandemic by deploying open source ventilators. Although it should be pointed out that personnel and training then become the limitations to deploying mass medical efforts, even if open source ventilators are available. So, future work is needed to create training materials and translate it into the languages spoken throughout the world as well.

\section{Conclusions}

There is clear technical potential for alleviating ventilator shortages during this and future pandemics using open source ventilator designs that can be rapidly fabricated using distributed manufacturing. The results of this review, however, found that the tested and peer-reviewed ventilator systems lacked complete documentation and that the current open systems that were documented were either at the very early stages of design or had undergone only early and rudimentary testing. With the considerably larger motivation of an ongoing pandemic, it is assumed these projects will garner greater attention and resources to make significant progress to reach a functional and easily replicated open source ventilator system. There is a large amount of technical future work needed to move open source ventilators up to the level considered adequate for scientific-grade equipment and further work still to reach medical-grade hardware. Future work is needed to achieve the potential of this approach not only on the technical side, but also by developing policies, updating regulations and securing funding mechanisms for the development and testing of open source ventilators for both the current COVID19 pandemic, as well as for future pandemics and for everyday use in low-resource settings.

\section{Data availability}

No data are associated with this article.

\section{Acknowledgments}

The author would like to thank all of those currently affiliated with the open source ventilator communities and the associated open hardware and 3-D printing communities for their inputs in the cited references.
1. World Health Organization: Critical preparedness, readiness and response actions for COVID-19: interim guidance, 7 March 2020. (No. WHO/COVID-19/ Community_Actions/2020.1). World Health Organization. 2020. Reference Source

2. The Lancet: COVID-19: too little, too late? Lancet. 2020; 395(10226): 755. PublMed Abstract | Publisher Full Text

3. Fisher D, Heymann D: Q\&A: The novel coronavirus outbreak causing COVID-19.
BMC Med. 2020; 18(1): 57.

PubMed Abstract | Publisher Full Text | Free Full Text

4. Ramsey L: Hospitals could be overwhelmed with patients and run out of beds and ventilators as the coronavirus pushes the US healthcare system to its limits. Business Insider. 2020.

Reference Source

5. Zhang X, Meltzer MI, Wortley PM: FluSurge---a tool to estimate demand for 
hospital services during the next pandemic influenza. Med Decis Making. 2006 26(6): 617-623.

PubMed Abstract | Publisher Full Text

6. Miller J: Germany, Italy rush to buy life-saving ventilators as manufacturers warn of shortages. Reuters. 2020

Reference Source

7. Neighmond P: As The Pandemic Spreads, Will There Be Enough Ventilators? NPR. 2020.

Reference Source

8. Rubinson L, Vaughn F, Nelson S, et al:: Mechanical ventilators in US acute care hospitals. Disaster Med Public Health Prep. 2010; 4(3): 199-206. PubMed Abstract | Publisher Full Text

9. Huang $\mathrm{HC}, \mathrm{Araz} \mathrm{OM}$, Morton DP, et al.: Stockpiling ventilators for influenza pandemics. Emerg Infect Dis. 2017; 23(6): 914-921.

PubMed Abstract | Publisher Full Text | Free Full Text

10. MacLaren G, Fisher D, Brodie D: Preparing for the Most Critically III Patients With COVID-19: The Potential Role of Extracorporeal Membrane Oxygenation. JAMA. 2020

PubMed Abstract | Publisher Full Text

11. Smetanin P, Stiff D, Kumar A, et al.: Potential intensive care unit ventilator demand/capacity mismatch due to novel swine-origin H1N1 in Canada. Can J Infect Dis Med Microbiol. 2009; 20(4): e115-e123.

PubMed Abstract | Publisher Full Text | Free Full Text

12. Ercole A, Taylor BL, Rhodes A, et al:: Modelling the impact of an influenza A/H1N1 pandemic on critical care demand from early pathogenicity data: the case for sentinel reporting. Anaesthesia. 2009; 64(9): 937-941. PubMed Abstract | Publisher Full Text

13. Stiff D, Kumar A, Kissoon N, et al.: Potential pediatric intensive care unit demand/capacity mismatch due to novel pH1N1 in Canada. Pediatr Crit Care Med. 2011; 12(2): e51-e57. PubMed Abstract | Publisher Full Text

14. Kanter RK: Would triage predictors perform better than first-come, first-served in pandemic ventilator allocation? Chest. 2015; 147(1): 102-108. PubMed Abstract | Publisher Full Text

15. Kim KM, Cinti S, Gay S, et al.: Triage of mechanical ventilation for pediatric patients during a pandemic. Disaster Med Public Health Prep. 2012; 6(2): 131-137. PubMed Abstract | Publisher Full Text

16. Neyman G, Irvin CB: A single ventilator for multiple simulated patients to meet disaster surge. Acad Emerg Med. 2006; 13(11): 1246-1249. PubMed Abstract | Publisher Full Text

17. Paladino L, Silverberg M, Charchaflieh JG, et al:: Increasing ventilator surge capacity in disasters: ventilation of four adult-human-sized sheep on a single ventilator with a modified circuit. Resuscitation. 2008; 77(1): 121-126. PubMed Abstract | Publisher Full Text

18. Farkas J: PulmCrit - Splitting ventilators to provide titrated support to a large group of patients. 2020 Reference Source

19. Siderits R, Neyman G: Experimental 3D Printed 4-Port Ventilator Manifold for Potential Use in Disaster Surges. Open Journal of Emergency Medicine. 2014; 2(3): 46-48 Publisher Full Tex

20. Older ventilators that used intermittent mandatory ventilation (IMV) by applying positive pressure at set intervals were hard to synchronize to patients that are spontaneously breathing, tended to be uncomfortable and dangerous, so patients would typically have would be given paralyzing medications for the respiratory musculature. Modern ventilators sense when patients are taking a breath, and synchronize with the patient. For splitters to work, this triggering would need to be separated from ventilator as well as offering appropriate valves for each patient. Also, each patient would need individual systems to blend oxygen and air to avoid either inadequate or excessive oxygenation.

21. Malatino EM: Strategic national stockpile: overview and ventilator assets. Respir Care. 2008; 53(1): 91-95.

PubMed Abstract

22. McNeil DG Jr: Hospitals Short on Ventilaters if Bird Flu Hits. 2006 Reference Source

23. Meltzer MI, Patel A, Ajao A, et al.: Estimates of the demand for mechanical ventilation in the United States during an influenza pandemic. Clin Infect Dis. 2015; 6060 Suppl 1: S52-S57.

PubMed Abstract | Publisher Full Text | Free Full Text

24. Crowder L: Ventilator blues: Infectious disease expert Tom Inglesby on the next major pandemic. Bull At Sci. 2018; 74(5): 340-347. Publisher Full Text

25. Folmer K: 'We'll take them all': Demand for ventilators spikes as coronavirus looms. ABC News. 2020.

Reference Source

26. Patrone D, Resnik D: Pandemic ventilator rationing and appeals processes. Health Care Anal. 2011; 19(2): 165-179.

PubMed Abstract | Publisher Full Text | Free Full Text

27. Boldrin M, Levine DK: Against intellectual monopoly (Vol. 8). Cambridge: Cambridge University Press. 2008.

Publisher Full Text

28. Pagano U: The crisis of intellectual monopoly capitalism. Cambridge J Econ.
2014; 38(6): 1409-1429.

Publisher Full Text

29. Peters J: Medical company threatens to sue volunteers that 3D-printed valves for life-saving coronavirus treatments. The Verge. 2020 Reference Source

30. Masnick M: SoftBank Owned Patent Troll, Using Monkey Selfie Law Firm, Sues To Block Covid-19 Testing, Using Theranos Patents. TechDirt. 2020. Reference Source

31. Kinsella NS: Against intellectual property. J Libert Stud. 2001; 15(2; SEAS SPR):

Reference Source

32. Boldrin M, Levine D: The case against intellectual property. Am Econ Rev. 2002; 92(2): 209-212.

Publisher Full Text

33. Pearce JM: A novel approach to obviousness: An algorithm for identifying prior art concerning 3-D printing materials. World Patent Information. 2015; 42 13-18.

Publisher Full Text

34. Laplume A, Anzalone GC, Pearce JM: Open-source, self-replicating 3-D printer factory for small-business manufacturing. Int J Adv Manuf Technol. 2016; 85(1-4): 633-642. Publisher Full Text

35. Sanchez FAC, Lanza S, Boudaoud H, et al:: Polymer Recycling and Additive Manufacturing in an Open Source context: Optimization of processes and methods. In Annual international solid freeform fabrication symposium, ISSF 2015. 2015; 1591-1600.

36. DeVor RE, Kapoor SG, Cao J, et al.: Transforming the landscape of manufacturing: distributed manufacturing based on desktop manufacturing (DM) 2. J Manuf Sci Eng. 2012; 134(4).

Publisher Full Text

37. Woern AL, Pearce JM: Distributed manufacturing of flexible products: Technical feasibility and economic viability. Technologies. 2017; 5(4): 71 Publisher Full Text

38. Hunt EJ, Zhang C, Anzalone N, et al.: Polymer recycling codes for distributed manufacturing with 3-D printers. Resources, Conservation and Recycling. 2015; 97: 24-30.

Publisher Full Text

39. Gwamuri J, Wittbrodt BT, Anzalone NC, et al.: Reversing the trend of large scale and centralization in manufacturing: The case of distributed manufacturing of customizable 3-D-printable self-adjustable glasses. Challenges in sustainability. 2014; 2(1): 30-40.

Publisher Full Text

40. Petersen EE, Pearce J: Emergence of home manufacturing in the developed world: Return on investment for open-source 3-D printers. Technologies. 2017; 5(1): 7 .

Publisher Full Text

41. Pearce JM: Materials science. Building research equipment with free, opensource hardware. Science. 2012; 337(6100): 1303-1304.

PubMed Abstract | Publisher Full Text

42. Pearce JM: Open-source lab: how to build your own hardware and reduce research costs. Elsevier. 2013. Publisher Full Text

43. Chagas AM: Haves and have nots must find a better way: The case for open scientific hardware. PLOS Biol. 2018: 16(9): e3000014. PubMed Abstract | Publisher Full Text | Free Full Tex

44. Damase TR, Stephens D, Spencer A, et al:: Open source and DIY hardware for DNA nanotechnology labs. J Biol Methods. 2015; 2(3): e24. PubMed Abstract | Publisher Full Text | Free Full Text

45. Daniel KF, Peter JG: Open-source hardware is a low-cost alternative for scientific instrumentation and research. Modern instrumentation. 2012; 1(2): 8-20. Publisher Full Text

46. Harnett C: Open source hardware for instrumentation and measurement. IEEE instrumentation \& measurement magazine. 2011; 14(3): 34-38. Publisher Full Text

47. Dryden MD, Fobel R, Fobel C, Wheeler AR: Upon the shoulders of giants: opensource hardware and software in analytical chemistry. Anal Chem. 2017; 89(8): 4330-4338.

Publisher Full Text

48. Pearce JM: Quantifying the value of open source hardware development Modern Economy. 2015; 6(01): 1-11.

Publisher Full Text

49. Pearce JM: Return on investment for open source scientific hardware development. Sci Public Policy. 2016; 43(2): 192-195. Publisher Full Text

50. Coakley M, Hurt DE: 3D printing in the Laboratory: Maximize Time and Funds with Customized and Open-Source Labware. J Lab Autom. 2016; 21(4): 489-495.

PubMed Abstract | Publisher Full Text | Free Full Text

51. Oberloier S, Pearce JM: General design procedure for free and open-source 
hardware for scientific equipment. Designs. 2018; 2(1): 2. Publisher Full Text

52. Niezen G, Eslambolchilar $\mathrm{P}$, Thimbleby $\mathrm{H}$ : Open-source hardware for medical devices. BMJ innov. 2016; 2(2): 78-83.

PubMed Abstract | Publisher Full Text | Free Full Text

53. Michaels RE, Pearce JM: 3-D printing open-source click-MUAC bands for identification of malnutrition. Public Health Nutr. 2017; 20(11): 2063-2066. Publisher Full Text

54. Ventola CL: Medical applications for 3D printing: current and projected uses. $P$ T. 2014; 39(10): 704-711.

PubMed Abstract | Free Full Text

55. Pearce JM: Maximizing Returns for Public Funding of Medical Research with Opensource Hardware. Health Policy and Technol. 2017; 6(4): 381-382. Publisher Full Text

56. Kats D, Spicher L, Savonen B, et al.: Paper 3D Printing to Supplement Rural Healthcare Supplies-What Do Healthcare Facilities Want? In 2018 IEEE Global Humanitarian Technology Conference (GHTC). 2018; 1-8). IEEE. Publisher Full Text

57. Tatham P, Loy J, Peretti U: Three dimensional printing-a key tool for the humanitarian logistician? Journal of Humanitarian Logistics and Supply Chain Management. 2015. Publisher Full Text

58. Saripalle $\mathrm{S}$, Maker $\mathrm{H}$, Bush A, et al:: 3D printing for disaster preparedness: Making life-saving supplies on-site, on-demand, on-time. In 2016 IEEE Global Humanitarian Technology Conference (GHTC). IEEE. 2016; 205-2008. Publisher Full Text

59. Mohammed MI, Wilson D, Gomez-Kervin E, et al:: The recycling of E-Waste ABS plastics by melt extrusion and $3 \mathrm{D}$ printing using solar powered devices as a transformative tool for humanitarian aid. 2018; (accessed on 19 April 2019) 2018; (accessed on 19 April 2019).

Reference Source

60. Savonen BL, Mahan TJ, Curtis MW, et al:: Development of a resilient 3-D printer for humanitarian crisis response. Technologies. 2018; 6(1): 30. Publisher Full Text

61. James E, James L: $3 D$ printing humanitarian supplies in the field. Humanit Exch. 2016; 66: 43-45.

Reference Source

62. Jones $\mathrm{R}$, Haufe $\mathrm{P}$, Sells $\mathrm{E}$, et al:: RepRap-the replicating rapid prototyper. Robotica. 2011; 29(1): 177-191. Publisher Full Text

63. Sells E, Bailard S, Smith Z, et al:: RepRap: the replicating rapid prototyper: maximizing customizability by breeding the means of production. In Handbook of Research in Mass Customization and Personalization: (In 2 Volumes). 2009; $568-580$.

Publisher Full Text

64. Bowyer A: 3D printing and humanity's first imperfect replicator. Addit Manuf. 2014; 1(1): 4-5. Publisher Full Text

65. Obydenkova S, Anzalone NC, Pearce JM: Prospects of applying 3-D printing to economics of remote communities. Journal of Enterprising Communities: People and Places in the Global Economy. 2018.

Publisher Full Text

66. Baechler C, DeVuono M, Pearce JM: Distributed recycling of waste polymer into RepRap feedstock. Rapid Prototyp J. 2013; 19(2): 118-125. Publisher Full Text

67. Zhong S, Pearce JM: Tightening the loop on the circular economy: Coupled distributed recycling and manufacturing with recyclebot and RepRap 3-D printing. Resources, Conservation and Recycling. 2018; 12(): 48-58. Publisher Full Text

68. Sanchez FAC, Boudaoud H, Hoppe S, et al.: Polymer recycling in an opensource additive manufacturing context: Mechanical issues. Addit Manuf. 2017; 17: 87-105.

Publisher Full Text

69. Dertinger SC, Gallup N, Tanikella NG, et al:: Technical pathways for distributed recycling of polymer composites for distributed manufacturing: Windshield wiper blades. Resources, Conservation and Recycling. 2020; 157: 104810. Publisher Full Text

70. Hart KR, Frketic JB, Brown JR: Recycling meal-ready-to-eat (MRE) pouches into polymer filament for material extrusion additive manufacturing. Addit Manuf. 2018; 21: 536-543. Publisher Full Text

71. Santander P, Sanchez FAC, Boudaoud H, et al:: Closed loop supply chain network for local and distributed plastic recycling for 3D printing: a MILPbased optimization approach. Resour Conserv Recy. 2020; 154: 104531. Publisher Full Text

72. Pavlo S, Fabio C, Hakim B, et al:: 3D-Printing Based Distributed Plastic Recycling: A Conceptual Model for Closed-Loop Supply Chain Design. In 2018 IEEE International Conference on Engineering, Technology and Innovation (ICE/ITMC). IEEE, 2018; 1-8.

Publisher Full Text

73. Woern AL, Byard DJ, Oakley RB, et al:: Fused Particle Fabrication 3-D Printing: Recycled Materials' Optimization and Mechanical Properties. Materials (Basel).
2018: 11(8): pii: E1413.

PubMed Abstract | Publisher Full Text | Free Full Text

74. Zander NE, Gillan M, Lambeth RH: Recycled polyethylene terephthalate as a new FFF feedstock material. Addit Manuf. 2018; 21: 174-182. Publisher Full Text

75. Mohammed MI, Das A, Gomez-Kervin E, et al:: EcoPrinting: investigating the use of $100 \%$ recycled acrylonitrile butadiene styrene (ABS) for additive manufacturing. In Proceedings of the 28th Annual International Solid Freeform Fabrication Symposium. 2017; 532-542. Reference Source

76. Mohammed M, Mohan M, Das A, et al.: A low carbon footprint approach to the reconstitution of plastics into 3D-printer filament for enhanced waste reduction. In DesTech 2016: Proceedings of the International Conference on Design and Technology. 2017; 234-241, Knowledge E. Publisher Full Text

77. Mohammed MI, Wilson D, Gomez-Kervin E, et al:: EcoPrinting: Investigation of Solar Powered Plastic Recycling and Additive Manufacturing for Enhanced Waste Management and Sustainable Manufacturing. In 2018 IEEE Conference on Technologies for Sustainability (SusTech). IEEE 2018; 1-6. Publisher Full Text

78. Mohammed MI, Wilson D, Gomez-Kervin E, et al: Investigation of closed-loop manufacturing with acrylonitrile butadiene styrene over multiple generation using additive manufacturing. ACS Sustainable Chemistry \& Engineering. 2019; 7(16): 13955-13969.

Publisher Full Text

79. Campbell I, Diegel O, Kowen J, et al.: Wohlers report 2018: 3D printing and additive manufacturing state of the industry: annual worldwide progress report. Wohlers Associates. 2018.

Reference Source

80. Wittbrodt BT, Glover AG, Laureto J, et al.: Life-cycle economic analysis of distributed manufacturing with open-source 3-D printers. Mechatronics. 2013, 23(6): 713-726

Publisher Full Text

81. Common open source licenses include the GNU General Public License (GPL) and the Creative Commons Attribution-ShareAlike license. Other copyleft licenses have been specifically designed for hardware include the CERN Open Hardware License $(\mathrm{OHL})$ and the TAPR Open Hardware License $(\mathrm{OHL})$. For more information see https://www.oshwa.org/definition/

82. Andreoli TE, Bennett C, Carpenter C, et al:: Cecil Essentials of Medicine $4^{\text {th }}$ edition. WB Saunders Company, 1997.

Reference Source

83. Hess D, Kacmarek RM, Kollef MH: Essentials of mechanical ventilation. New York: McGraw-Hill, Health Professions Division, 1996.

84. Tobin MJ: Principles and practice of mechanical ventilation. McGraw Hill Professional. 2010.

Reference Source

85. Owens W: The Ventilator Book: Second Edition. First Draught Press. 2018.

86. Aston D, Rivers A, Dharmadasa A: Equipment in Anaesthesia and Critical Care: A complete guide for the FRCA. Royal College of General Practitioners. 2013. Reference Source

87. Bein T, Grasso S, Moerer O, et al:: The standard of care of patients with ARDS ventilatory settings and rescue therapies for refractory hypoxemia. Intensive Care Med. 2016; 42(5): 699-711.

PubMed Abstract | Publisher Full Text | Free Full Text

88. Carpio ALM, Mora JI: Ventilator management. In StatPearls [Internet]. StatPearls Publishing. 2019.

PubMed Abstract

89. Olive S: Practical procedures: oxygen therapy. Nurs Times. 2016; 112(1-2): 12-14.

PubMed Abstract

90. Pham T, Brochard LJ, Slutsky AS: Mechanical ventilation: state of the art. Mayo Clin Proc. Elsevier, 2017; 92(9): 1382-1400. PubMed Abstract | Publisher Full Text

91. Kerechanin CW, Cytcgusm PN, Vincent JA, et al:: Development of field portable ventilator systems for domestic and military emergency medical response. John Hopkins Apl Tech Digest. 2004; 25(3). Reference Source

92. Jürß H, Degner M, Ewald H: A new compact and low-cost respirator concept for one way usage. IFAC-PapersOnLine. 2018; 51(27): 367-372. Publisher Full Text

93. Fuchs $\mathrm{P}$, Obermeier J, Kamysek S, et al.: Safety and applicability of a pre-stage public access ventilator for trained laypersons: a proof of principle study. BMC Emerg Med. 2017; 17(1): 37.

PublMed Abstract | Publisher Full Text | Free Full Text

94. Fogarty M, Orr J, Westenskow D, et al.: Electric Blower Based Portable Emergency Ventilator. 2013.

Reference Source

95. Shahid M: Prototyping of Artificial Respiration Machine Using AMBU Bag Compression. In 2019 International Conference on Electronics, Information, and Communication (ICEIC), IEEE. 2019; 1-6.

Reference Source

96. Al Husseini AM, Lee HJ, Negrete J, et al:: Design and prototyping of a low-cost 
portable mechanical ventilator. Transactions of the ASME-W-Journal of Medical Devices. 2010; 4(2): 027514

Reference Source

97. Powelson SK: Design and prototyping of a low-cost portable mechanical ventilator (Doctoral dissertation, Massachusetts Institute of Technology) 2010. Reference Source

98. Oxer J, Blemings H: Practical Arduino: cool projects for open source hardware. Apress. 2011.

Publisher Full Text

99. Williams D, Flory S, King R, et al:: A low oxygen consumption pneumatic ventilator for emergency construction during a respiratory failure pandemic. Anaesthesia. 2010; 65(3): 235-242. PubMed Abstract | Publisher Full Text

100. Simon BA, Mitzner W: Design and calibration of a high-frequency oscillatory ventilator. IEEE Trans Biomed Eng. 1991; 38(2): 214-218. PubMed Abstract | Publisher Full Text

101. Coetzee G: Ultimate Medical Hackathon: How Fast Can We Design And Deploy An Open Source Ventilator? Hackaday. 2020. Reference Source

102. Manual Ventilation for the Developing World. "OEDK - Rice University Member public profile." 2015 Reference Source

103. IGS Low Cost Ventilator. (it is interesting to note this is a request for funding that received only $1 \%$ of the request) Reference Source

104. Open WHO: "Clinical Care Severe Acute Respiratory Infection I OpenWHO. Reference Source

105. Butler C: 'Pandemic ventilator' could offer solution in potential 'worst case' coronavirus scenario. CBC Reference Source

106. Nilsiam Y, Pearce JM: Open source database and website to provide free and open access to inactive US patents in the public domain. Inventions. 2016; 1(4): Publisher Full Text

107. Chen JV, Dang ABC, Lee CS, et al:: 3D printed PLA Army-Navy retractors when used as linear retractors yield clinically acceptable tolerances. $3 D$ Print Med. 2019; 5(1): 16 PubMed Abstract | Publisher Full Text | Free Full Text

108. Heikkinen IT, Kauppinen C, Liu Z, et al.: Chemical compatibility of fused filament fabrication-based 3-D printed components with solutions commonly used in semiconductor wet processing. Addit Manuf. 2018; 23: 99-107. Publisher Full Text

109. Reich MJ, Woern AL, Tanikella NG, et al:: Mechanical properties and applications of recycled polycarbonate particle material extrusion-based additive manufacturing. Materials (Basel). 2019; 12(10): pii: E1642. PubMed Abstract | Publisher Full Text | Free Full Text

110. Mohammed Ml, Cadd B, Peart G, et al:: Augmented patient-specific facial prosthesis production using medical imaging modelling and 3D printing technologies for improved patient outcomes. Virtual and Physical Prototyping. 2018; 13(3): 164-176. Publisher Full Text

111. Wijnen B, Hunt EJ, Anzalone GC, et al.: Open-source syringe pump library. PloS One. 2014; 9(9): e107216. PubMed Abstract | Publisher Full Text | Free Full Text

112. Akash $\mathrm{K}$, Kumar MP, Venkatesan N, et al:: A single acting syringe pump based on Raspberry Pi-SOC. In 2015 IEEE International Conference on Computational Intelligence and Computing Research (ICCIC). IEEE, 2015; 1-3. Publisher Full Text

113. Amarante LM, Newport J, Mitchell M, et al:: An open source syringe pump controller for fluid delivery of multiple volumes. eNeuro. 2019; 6(5) pii: ENEURO.0240-19.2019 PubMed Abstract | Publisher Full Text | Free Full Text

114. Surya V, Shreya Kulkarni KD: Ocular drug delivery system using open-source syringe pump. Asian J Pharm Clin Res. 2018; 11(6): 152-157. Publisher Full Text

115. Pusch K, Hinton TJ, Feinberg AW: Large volume syringe pump extruder for desktop 3D printers. HardwareX. 2018; 3: 49-61. PubMed Abstract | Publisher Full Text | Free Full Text

116. Booeshaghi AS, da Veiga Beltrame E, Bannon D, et al.: Design principles for open source bioinstrumentation: the poseidon syringe pump system as an example. bioRxiv. 2019; 521096.

Publisher Full Text
117. Lake JR, Heyde KC, Ruder WC: Low-cost feedback-controlled syringe pressure pumps for microfluidics applications. PLOS One. 2017; 12(4): e0175089. PubMed Abstract | Publisher Full Text | Free Full Text

118. Garcia VE, Liu J, DeRisi JL: Low-cost touchscreen driven programmable dual syringe pump for life science applications. HardwareX. 2018; 4: e00027. Publisher Full Text

119. Cubberley MS, Hess WA: An inexpensive programmable dual-syringe pump for the chemistry laboratory. J Chem Educ. 2017; 94(1): 72-74. Publisher Full Text

120. Carvalho MC, Murray RH: Osmar, the open-source microsyringe autosampler. HardwareX. 2018; 3: 10-38. Publisher Full Text

121. LeSuer RJ, Osgood KL, Stelnicki KE, et al.: OMIS: The Open Millifluidic Inquiry System for small scale chemical synthesis and analysis. HardwareX. 2018; 4 e00038. Publisher Full Text

122. Klar V, Pearce JM, Kärki P, et al.: Ystruder: Open source multifunction extruder with sensing and monitoring capabilities. HardwareX. 2019; 6: e00080. Publisher Full Text

123. Zuo MZ, Huang YG, Ma WH, et al.: Expert Recommendations for Tracheal Intubation in Critically ill Patients with Noval Coronavirus Disease 2019. Chin Med Sci J. 2020; 10.

PubMed Abstract | Publisher Full Text

124. Goehrke S: 3D Printing Against Coronavirus: Who And How To Help. Fabaloo. Reference Source

125. Prủša J: From Design to Mass 3D printing of Medical Shields in Three Days. 2020. Reference Source

126. Parker JC, Hernandez LA, Peevy KJ: Mechanisms of ventilator-induced lung injury. Crit Care Med. 1993; 21(1): 131-143. PubMed Abstract | Publisher Full Text

127. Dreyfuss $D$, Saumon G: Ventilator-induced lung injury: lessons from experimental studies. Am J Respir Crit Care Med. 1998; 157(1): 294-323. PubMed Abstract | Publisher Full Text

128. Slutsky AS, Ranieri VM: Ventilator-induced lung injury. N Engl J Med. 2013 369(22): 2126-2136 Publisher Full Text

129. Ricard JD, Dreyfuss D, Saumon G: Ventilator-induced lung injury. Eur Respir J Suppl. 2003; 42 (42 suppl): 2s-9s. PubMed Abstract | Publisher Full Text

130. Dos Santos CC, Slutsky AS: Invited review: mechanisms of ventilator-induced lung injury: a perspective. J Appl Physiol (1985). 2000; 89(4): 1645-1655. PubMed Abstract | Publisher Full Text

131. Tremblay LN, Slutsky AS: Ventilator-induced lung injury: from the bench to the bedside. In Applied Physiology in Intensive Care Medicine. Springer, Berlin, Heidelberg. 2006; 357-366. Publisher Full Text

132. Gattinoni $L$, Protti $A$, Caironi $P$, et al:: Ventilator-induced lung injury: the anatomical and physiological framework. Crit Care Med. 2010; 38(10Suppl): S539-S548.

PubMed Abstract | Publisher Full Text

133. Cressoni M, Gotti M, Chiurazzi C, et al:: Mechanical Power and Developmen of Ventilator-induced Lung Injury. Anesthesiology. 2016; 124(5): 1100-1108. PubMed Abstract | Publisher Full Text

134. Brochard L, Roudot-Thoraval F, Roupie E, et al:: Tidal volume reduction for prevention of ventilator-induced lung injury in acute respiratory distress syndrome. The Multicenter Trail Group on Tidal Volume reduction in ARDS. Am J Respir Crit Care Med. 1998; 158(6): 1831-1838. PubMed Abstract | Publisher Full Text

135. Gattinoni L, Carlesso E, Cadringher $P$, et al.: Physical and biological triggers of ventilator-induced lung injury and its prevention. Eur Respir J Suppl. 2003 47(47 suppl): $15 \mathrm{~s}-25 \mathrm{~s}$

PubMed Abstract | Publisher Full Text

136. Gompertz S, Carr E: Coronavirus: Plan to ramp up ventilator production 'unrealistic'. BBC. 2020. Reference Source

137. Koch VG, Roxland BE: Unique proposals for limiting legal liability and encouraging adherence to ventilator allocation guidelines in an influenza pandemic. DePaul J Health Care L. 2011; 14: 467.

Reference Source 


\title{
Open Peer Review
}

\section{Current Peer Review Status:}

\section{Version 1}

Reviewer Report 22 April 2020

https://doi.org/10.5256/f1000research.25328.r61802

(C) 2020 Mohammed M. This is an open access peer review report distributed under the terms of the Creative Commons Attribution License, which permits unrestricted use, distribution, and reproduction in any medium, provided the original work is properly cited.

\author{
Mazher Mohammed \\ School of Design and Creative Arts, Loughborough University, Loughborough, UK
}

\section{Introduction}

The manuscript presents a review of open sources ventilators with particular emphasis towards applications in the COVID-19 pandemic during the early phases of 2020. Given the submission date of the manuscript, which has coincided with the emergence of the COVID-19 pandemic, the review is very topical, in addition to being thought provoking and insightful. COVID-19 disease is caused by severe acute respiratory syndrome coronavirus 2 (SARS-CoV-2), where the presenting symptoms of a patient are predominantly based upon respiratory ailments, requiring ventilation based equipment to treatment the most severe of cases. As the virus infiltrates a greater frequency of the general population, the availability of ventilation based products has rapidly become one of the primary causes for concern not only in developing, but in developed economics. Given the disruption of standard medical device supply chains during a pandemic, a viable alternative to meet the demand for ventilation equipment from healthcare providers is to turn to communities of designers, engineers, industrial specialists and knowledgeable maker enthusiasts to develop easily accessible, low-cost and open source alternatives to traditional devices. The manuscript is therefore a vital piece of documentation to assist researchers in global efforts to create ventilator alternatives. Equally, the manuscript does an exceptional job at highlighting the current state of the art in this area with balanced and considered conclusions throughout. I would therefore very much recommend this article for indexing, which will be of great interest to the scientific community and those seeking to develop their own open source solutions.

\section{Recommendations and Thoughts}

It is noted that the article is based on the premise of discussing ventilator technology which are deemed open source. As review manuscripts generally attract a wider target audience that scientific bodies of work, it would seem appropriate for the author to define what is meant by open source, for the benefit of unfamiliar readers. Indeed, one may see general scientific publications are open source information by virtue of the information being in the public domain. However, it is clear that the authors perception of this would require a deeper level of 'disclosure' of the innovations presented by various research groups to allow for ready duplication and 
adoption of such systems. This is starkly evident later in the manuscript during discussions of existing literature. Therefore, the distinction of what constitutes open source in this context should be explicitly defined, ideally within the introduction.

In light of the rapidly evolving nature of the pandemic and the volume of initiatives that are attempting to provide viable, often, open source solutions, there is likely to be some developments that have not been addressed in the review. Generally, the author has done an exemplary job of drawing the readers attention to many of the most topical and noteworthy examples. However, one would imagine as we approach the end of the pandemic period that there is likely to be a wealth of additional technologies which will have surfaced and so perhaps a follow up review may be justified, ideally inviting multiple authors involved in such projects to contribute. It is however noted that certain information within the manuscript has since evolved, specifically relating to the comment in the first paragraph of the introduction, where it is mentioned that '.......for a recent example, consider the fact that a manufacturer threatened to sue a maker for 3-D printing life-saving valves in Italy for patent infringement....' Upon further development of this story, the company had made official statement to clarify that they did not attempt to sue the party which made ventilator valve parts but had primarily withheld designs based upon medical device regulation. Although withholding designs during this particular circumstance when supply chain needs could not be met resulting in potential mortality of patients, there is an argument to disclose such information despite legal implications. However, this is very much different to the notion of the company suing the Italian firm. At the time of writing the article this would not have been known to the author, but given the controversial nature of the comment, I would request the author to reword this sentence to reflect the final outcome of this case study.

During the introduction when discussing the very many technologies available to the open source community, the discussion preferentially revolves around the use of rep-rap 3D printing, under the notion of digital fabrication technologies which have distributed manufacturing potential. This is a very important point to make by the author as distinctions are made as to why this approach would provide added value within the context of a pandemic. In particular, designs may be shared both at a national and international level using internet based data transfer, while leveraging manufacturing and technical capacity closer to the point of use. Such capacity has long been utilised by the open source community, providing strong resilience in instances when typical supply chains are disrupted, as would be the case during a pandemic. However, this discussion appears to be somewhat incomplete for readers who are unfamiliar with this approach of manufacturing. More specifically, it may be useful for future readers to hear some mention of other digitally driven distributed technologies, such as milling/CNC machining, laser engraving/etching and other digitally controlled tools. Indeed, several of these technologies would serve to reduce or eliminate the perceived limitations of 3D printing both in terms of manufacturable materials and speed of manufacturing. Please could the author include some additional discussion here to contextualise available options to the open source community with respect to digital and distributed manufacturing.

The author presents an eloquent attempt to discuss both the academic and non-academic ventilation systems, citing many interesting studies and raising most of the key facets of each respective technology. Following from the previous comments regarding the open source nature of a given study, it is highlighted that sadly many academic studies, though presenting some remarkable feats of engineering, simply do not provide sufficient information to allow for other researchers and experts to duplicate a respective ventilation system. This is indeed a shame and 
highlights perhaps a necessity for researchers to adopt a more open frame work of reporting academic findings and equally for reviewers to encourage and accept such ways of reporting. In light of major global health catastrophes such as pandemics, such openness within the literature may in fact prove advantageous to hasten innovations to tackle the detrimental effects on a given population.

The discussion on the current open source efforts appears to cover several of the major projects to the awareness of this reviewer, but more crucially provides a good cross section of important developmental aspects to inform the reader. As highlighted previously, given the rapidly evolving nature of the pandemic and the wiliness and passion of researchers and technical experts, new attempts to create ventilation products are arising on a weekly, if not daily basis from groups around the world. Therefore, in this reviewer's opinion, to cover all such attempts would be impractical but also unnecessary given that the overlap of technical development with existing projects. As with the previous section, it would have been good to present annotated diagrams and a summary chart/table of the systems broken down into the primary attributes that fulfil the requirement for ventilation. In reading this section it was difficult to surmise how these efforts were truly moving towards a functional ventilation device. One of the more noteworthy examples from Rice University, with credible data to back the developments to date was sadly hindered by component failure after only a 11-hour evaluation period, which falls considerably short of a functional ventilator. Clearly, several if not all examples highlighted by the author raise several notes of caution toward open source design, namely the clarity and robustness of evaluation, which lacks the rigour of typical academic scrutiny in addition to the lack of standardisation of components which are suitable for purpose. Arguably, the author to varying degrees' highlights this by stating the case studies in question are either in the very preliminary stages of investigation, show a lack of relevant performance data or a Bill of Materials (BOM) which enables scrutiny of the components employed. I believe there is a missed opportunity of discussing these elements in greater depth, which is vitally required if open source ventilators are to truly enter mainstream acceptance and use. I would very much welcome further discussion on limitations with appropriate recommendations, which both do not stifle the breadth of design ideas by the community, but also provide substantiative guidance to direct those involved to be mindful of critical milestones and 'codes of best practise' during the journey from inception of idea to final working and 'usable' ventilator. For example, looking at open source efforts for Personal Protective Equipment (PPE) we see that the 3D Printing community rapidly converged towards the preferential use of PETG polymers for manufacturing, owing to the factors of mechanical stiffness providing a semi flexible yet robust part, and importantly biocompatibility for limited human contact and being food grade to allow ease of decontamination. Equally, strict protocols were developed to minimise contamination of parts during printing, handling and shipping to both reduce the spread of the virus within the supply chain and to follow some element of best practise, similar to constraints set by medical device companies upon their manufacturing procedures. It would be very useful to the open source community if the author would share their thoughts in more explicit detail to provide a template that could be built upon for future efforts, outlining best practise from initial design ideation to working prototype. Arguably, the imperative of this is much greater than with PPE given potential intrusive nature of ventilation systems providing a clear route to internal infection through the lungs.

One element that appears to be missed in the present review is an overview of current commercial systems and evaluation of their performance characteristics to be both efficacious and crucially to prevent unintended harm to a patient. The author does cite an existing review of 
commercial ventilators by Pham et al, and so it would be unnecessary to conduct a repeat of this work. However, what would be relevant in the present manuscript is a discussion focusing on the regulatory and quality assurance aspects and how these would align and differ in the approach of open source ventilation systems. Indeed, commercial devices must adhere to the very strictest regulatory scrutiny to be classified and used as a medical device, particularly given the invasive nature of their operation to either supplement or take complete control of a patients breathing. As such there are tightly regulated frameworks of 'fail safes' to ensure that every component used falls within acceptable usage limits, that construction of such devices follow strict regimes for assembly and minimisation of contamination, that tests are conducted to evaluate the working performance of each device, that there is a robust training and best practise usage protocol, amongst many other safety measures and supply chain demands. Arguably, one of the biggest reservations by the commercial sector regarding open source hardware for medical device technology are the lack of process control, quality assurances and regulations regarding technological development and best practise. It would be valuable for the readers to have some insight into what safety and evaluation procedures that are conducted and how such measures would be replicated in open sources systems in general terms, highlighting key challenges which can be built upon for the future discussion.

The final sections of the review offer an exceptional summary of the state of art in the field of open source ventilators, highlighting several challenges and opportunities in this space. The author rightly highlights the very early stages open source ventilations systems currently are at and that we should not expect these systems to be working within a clinical setting in the immediate future. Despite this, I for one feel optimistic given the current work that is underway, our ability to access a wealth of digital knowledge, alongside the availability of hardware and manufacturing resources at our disposal. Arguably, the open source community has never been better equipment to make positive impact on the world during the COVID-19 pandemic. It is also the opinion of the reviewer that there remains many more opportunities for both growth of the open source community and to leverage the expertise synergistically with other academic groups to more rapidly advance our preparedness for emergency situations.

Reflecting upon the manuscript, I could not help but feel there are differing schools of thought that of the traditionalist and the open source innovator. The traditionalist will operate with robust scientific rigour but will provide limited information scientific manuscripts, be open to patent and potentially restrict free flow of concepts and with respect to medical technology will strictly follow medical regulatory frameworks. The open source innovator is generally driven by an overwhelming sense of openness and transparency in their work, with the belief this will help proliferate and see ideas adopted faster for anyone's benefit, albeit on some occasions operate with a naivety towards regulatory and best practise aspects. Initial discussions by the author drew distinction between efforts of the academic and non-academic communities, which very loosely are comprised of these two types of innovators, with the exception of a few 'maverick' academic groups. However, there was little discussion of strategies as to how these two communities may come together in cooperation and bridge any perceived differences in thinking. Clearly the academic community prides its outcomes based on empirical evidence, the careful scrutiny of data, alongside objective design performance metrics, attributes that the authors clearly outlines as shortfalls of the general open source community. Conversely, the non-academic community provides a wealth of creativity, ingenuity, alongside technical prowess, finding often remarkable and highly efficacious solutions working with limited resources and minimal dependency of specific supply chains. I would therefore strongly welcome the author to add further discussion 
towards strategies on how both communities, which for the most part work independently, could align agendas to realise opportunities that transcend the sum of the two parts. Indeed, I think it more critical for the open source community, based upon the reflection of the author, to be more engaged in traditional scientific process and to incorporate this into their thinking to hasten product development for evaluation.

One element that gave me considerable food for thought, was the notion that developing nations have a perceived advantage during global health emergencies due to their more relaxed legal and regulatory frameworks to deploy open source ventilator systems. I am not entirely convinced that this is the case and indeed the author makes several valid arguments to the contrary, mainly that the technology is not significantly mature to function as intended and without consequence. Such suggestions can indeed have several unpleasant connotations from a legal and ethical standpoint and so I would encourage the reviewer to consider an amendment to this comment. Ultimately, I believe it was not the authors intension to imply this given previous discussions, however the context of this point should be framed better.

\section{Summary}

Overall, despite the sombre theme of the review, the author has done an admirable job of bringing together all the relevant themes relating to open source ventilation systems. One of biggest take home messages from the review is how much potential exists with the open source community to provide cost effective, robust and timely medical device solutions, which may be far less susceptible to supply chain disruption and leverage a greater capacity for localised fabrication using the distributed manufacturing model. This capacity can only be realised by continued development of existing open source projects, increased dialogue with academic groups to work collaboratively to validate and iteratively improve ventilation system concepts for maximum efficacy. Equally, there is a clear need for regulatory reform which appreciates the evolving circumstances during a global health crisis and could provide an alternative framework to leverage capacity outside of typical medical supply chains to supplement efforts on the ground, as and when appropriate. What this framework should look like is another debate entirely, but this article makes an elegant argument for the debate to be had.

Despite the infancy of open source ventilation systems, much potential exists and it is an exciting time for developers to continue their efforts towards working solution. It is exciting to see what may be a paradigm shift in how we perceive and operate globally in the medical device sector, particularly in light of the recent issues during the COVID-19 pandemic, which have decimated supply chains, while the shear volume of cases has put a drain on medical resources. The pandemic has already seen the use of open source designs, manufactured in a distributed manner, make impact to supplement shortfalls in PPE equipment. Could the same in time be true for ventilator technologies based on the balance of growing demand and available resources? Only time will tell. I reiterate the relevancy of the article by the author and the manuscript has been a very thought provoking document to read and digest. I would whole heartedly recommend this article for publication and encourage researcher and technologist in the field to draw inspiration from the insightful and thought provoking arguments outlined. I do welcome a time when the lessons we are learning during the pandemic lead to a more caring and equitable world for us all, and it feels from a technological standpoint, that open source innovation will be part of that story.

\section{Additional minor points for consideration}


The hyperlink for Ref 82 needs revising as it links to an error page.

One the first paragraph of page 4 'breadth' has mistakenly been used in place of 'breath'. Additionally there are some minor grammatical errors toward the end of this same paragraph that need amending, specifically the sentence starting with 'texts area available for the

Generally speaking, it would have been very useful to contextualise much of the discussion with annotated diagrams of several key open source innovations, to give the reader a real feel for the types of devices in development. Indeed, this is typical of many academic based reviews of the scientific and gray literature. Unfortunately, this has not been the case in the present manuscript and I would invite the author to consider such an amendment.

Is the topic of the review discussed comprehensively in the context of the current literature?

Yes

Are all factual statements correct and adequately supported by citations? Yes

Is the review written in accessible language?

Yes

Are the conclusions drawn appropriate in the context of the current research literature? Yes

Competing Interests: No competing interests were disclosed.

Reviewer Expertise: Medical Devices, Bioengineering, Product Design, Sustainable Technologies and Materials, Open Source Hardware

I confirm that I have read this submission and believe that I have an appropriate level of expertise to confirm that it is of an acceptable scientific standard, however I have significant reservations, as outlined above.

Author Response 28 Apr 2020

Joshua M. Pearce, Michigan Technological University, Houghton, USA

Thank you for the rigorous and exceptionally detailed review.

Following your recommendation, I have added a much more explicit section detailing the meaning of open source as well as provide examples of it being misused.

I have removed the now incorrect example of the manufacturer suing over reverse engineered valves. Although it may be interesting to note I contacted the individual who reversed engineered them before the initial article was published and I have yet to receive 
the STL files.

I share your frustration with the current lack of appropriate sharing. I have included a more detailed review of the existing designs - but as you point out it is impractical to do everything in such a rapidly changing field where websites are being updated hourly or faster. I have declined to develop diagrams - even if I could find appropriately licensed images as a summary because of this rapidly changing nature. Particularly in mechanical designs because those appear to be the most often altered.

I have expanded considerably what the files are for in open hardware to help better introduce those outside of the open hardware community to the concept as well as make it clearer why they need to be included.

I have brought in an example from the PPE community.

In addition, following your recommendation I have attempted to provide some best practices in terms of 'when to share' in the discussion. This is meant to bridge the gap between the traditionalist and maker philosophies you discuss.

After considering your points and those of the other reviewers about the advantages of less developed regulatory systems I have simply removed this entirely.

I have corrected the minor mistakes you pointed out - thank you for finding them.

Lastly, I don't think that a complete review of all the legal hurdles and regulatory framework needed in this technical space can be done here - it needs a completely separate review. We have a major problem here because even some of the standards are not available. When an artificial lung company contacted their customers on my behalf to get a testing protocol they referred me to a long list of ASTM standards which I was not able to acquire through my relatively-well-resourced University library. I purchased the first one and was disappointed to find that it mostly contained references to other standards and a shocking dearth of useful technical information. As there is a conflict of interest between the publishers of such standards and providing all the information in a single location that is freely available for designers to help in a pandemic, this represents one of the largest hurdles. Some good-willed publishers have provided open access to some of their documents during the pandemic. This is a nice start but a better approach is to use public funding to provide open access documentation as the cost and opacity of these standards provide a barrier to open source ventilator development and as I pointed out an unacceptable state during an emergency.

Competing Interests: None 
(C) 2020 Farre $\mathbf{R}$. This is an open access peer review report distributed under the terms of the Creative Commons Attribution License, which permits unrestricted use, distribution, and reproduction in any medium, provided the original work is properly cited.

\section{Ramon Farre}

Unit of Biophysics and Bioengineering, School of Medicine and Health Sciences, University of Barcelona, Barcelona, Spain

This review by Prof. Pierce is an excellent and timely piece of work. I think the author is to be commended for this panoramic perspective on the current state of the art in the open source field of mechanical ventilators for acute respiratory failure. In addition to subscribing to Prof.

Bowman's extensive comments, I would particularly like to emphasize how important it is that open access contributions regarding medical devices be made in the context of multidisciplinary cooperation between professionals from different fields. In fact, unlike many other open access development areas, where the proposed devices or products can be used by a wide variety of users, medical devices focus on very specific end users: the doctors responsible for diagnosing and treating the patients. Therefore, any proposal for open access in medical devices must be not only technically sound and cost-effective, but, most importantly, safe and clinically applicable in real-life clinical routine. Consequently, as clearly stated in Professor Pierce's paper, realistically testing new developments is a critical step. Unfortunately, it is not unusual for some new open access contributions for medical applications to be the result of developments by authors drawn exclusively from the technological field, with the result that the proposed devices exhibit applicability limitations that seem obvious to clinicians who are potential users. Therefore, to advance the extension of the open access approach, it is important to make an effort to actively involve health professionals for both design and testing, trying to publish contributions in medical journals, not only in publications focused exclusively on open access. A very recent work, exactly in the field of developing open access mechanical ventilators for resource-poor areas, shows an example of a team of professionals covering the fields of biomedical engineering, respiratory physiology, physiotherapy and respiratory clinical medicine ${ }^{1}$. This multidisciplinary team has conceived, developed and tested a novel non-invasive pressure support ventilator following the conventional method of evaluating ventilators (bench tests in simulated patients and preclinical evaluation in volunteers) and has published the results in a prestigious journal of pneumology. To end my review of Prof. Pierce's excellent work, I would mention an open ethical issue about the requirements for medical devices to be used in resource-poor areas. It is important that these devices have the same high standard level as those approved for use in developed countries (e.g. CE / FDA marks). But it is also important that until the industry can provide such medical devices at affordable prices for LMICs, patients are not deprived of life-saving therapies. Finding a balance on this ethical-legal issue is difficult but fundamental.

\section{References}

1. Garmendia O, Rodríguez-Lazaro M, Otero J, Phan P, et al.: Low-cost, easy-to-build non-invasive pressure support ventilator for under-resourced regions: open source hardware description, performance and feasibility testing. European Respiratory Journal. 2020. Publisher Full Text

\section{Is the topic of the review discussed comprehensively in the context of the current literature?}


Yes

Are all factual statements correct and adequately supported by citations?

Yes

Is the review written in accessible language?

Yes

Are the conclusions drawn appropriate in the context of the current research literature? Yes

Competing Interests: No competing interests were disclosed.

Reviewer Expertise: Respiratory mechancs, Respiratory medical devices, Biomedical engineering.

I confirm that I have read this submission and believe that I have an appropriate level of expertise to confirm that it is of an acceptable scientific standard.

Author Response 28 Apr 2020

Joshua M. Pearce, Michigan Technological University, Houghton, USA

Thank you for the careful and constructive review.

I have included your well-reasoned point about the need for multi-disciplinary collaboration, the need to involve medical personnel, and to aim to publish in the medical literature.

In addition, I have included a deep review of Garmendia et al. design. A sincere thanks for pointing this out as well as for the work itself.

Thank you for the point about ethics - to account for this I have added several points about this in the discussion.

Competing Interests: None

Reviewer Report 02 April 2020

https://doi.org/10.5256/f1000research.25328.r61799

(c) 2020 Bowman R. This is an open access peer review report distributed under the terms of the Creative Commons Attribution License, which permits unrestricted use, distribution, and reproduction in any medium, provided the original work is properly cited.

Richard Bowman

Department of Physics, University of Bath, Bath, UK 
This is a really good, thorough review of open source ventilators, including both a good technical background, a review of existing peer reviewed projects, and a summary of current efforts. I would thoroughly recommend it to anyone considering joining or using an open source ventilator project, as it's particularly good at pointing to some relevant literature that describes the requirements and principles of operation. The conclusion of the article is that we're not there yet most of the published designs are not sufficiently complete to be easily replicated, while most of the current open projects are not rigorously tested.

The review of peer reviewed articles is interesting and does a good job of rating the different solutions in terms of openness; it is disappointing that these articles don't generally give sufficient information to reproduce the ventilator, but also unsurprising. This lends a great deal of weight to the current move towards more openness in science, where protocols, data, and schematics can be shared in data archives along with papers - but of course that's rarely done retrospectively.

The review of "internet and gray literature" seems objective and reasonable to me, and while such a review cannot possibly stay exhaustive given the frequency with which such projects are appearing, it does seem to cover many of the projects I've heard of. More important than an exhaustive list, however, is the discussion of the common issues to most of the DIY projects - the need for careful testing, quality control, and proper authorisation. Most discussions have focused only on technical validation - but as the author rightly points out, this is not the only way medical devices must be assessed. At least as pressing as the technical challenge is the difficulty of getting new suppliers and new devices through a quality assurance process that gives medical professionals the confidence that they can safely use said devices.

Openness is an important, and often surprisingly contentious, issue. Of the projects that are discussed, only relatively few make available complete designs for their solution. This is particularly surprising in the case of some projects from high-profile institutions that have already been widely reported in the media as "open" while not yet having released any designs. The commonly-accepted practice in open software is that complete designs, including source code and documentation, are made available to the public, and that a project is not considered open until this happens. Similar norms are being established for open hardware projects, supported by organisations such as OSHWA and GOSH.

Given the safety-critical nature of a ventilator, it's reasonable to be reluctant to release untested designs out of a desire to be responsible. Given the time-critical situation, sharing documentation and designs may also be considered lower priority than product development. However, the intent to share a design in the future misses the myriad benefits of open hardware - in terms of scrutiny, feedback, and improvements from the community. It also stifles the development of a community around the design, and there are many cases of promised openness never materialising. My own view is that projects ought not to claim openness until their designs are publicly available under an appropriate license, but there are definitely valid ethical and practical concerns here, and I would welcome an open debate on the best way forward.

The one statement in the article that I'm slightly troubled by is the suggestion that developing countries may be at an advantage due to their less robust regulatory systems. Firstly, while it is true that many countries in the Global South do have less formal economies, their regulations are often very tightly aligned with those in richer nations - for example, the Tanzanian medical device regulations closely mirror those used in the EU. If different standards are adhered to, it may be 
because the regulations are not implemented fully, rather than because the government has intentionally applied lower standards. Also, the better-resourced regulatory bodies in rich nations are more able to accelerate the process of approval if needed; it is not clear to me that a medical device would clear the bureaucratic hurdles and achieve approval any faster in a developing country, indeed the process can be much slower. It is also a very thorny ethical issue to trial medical interventions in the Global South that would not pass ethical scrutiny in richer nations, particularly as the interventions are often being proposed by people from said richer nations. I don't think the author is suggesting this, but I do feel it's a point worth highlighting. While there is often an argument made that low quality medical supplies may be better than nothing, it is also reasonable to expect that developers of technology shouldn't do anything to citizens of Low and Middle-Income Countries (LMICs) that they wouldn't do to patients in their own nation. Indeed, most ethical review panels in the UK apply exactly this criterion.

The challenge of creating a safety-critical medical device that can be produced in a distributed manner is significant, and I think the article reflects this. I could not agree more with the statement that "technical validation may not be enough" and would probably go further, to say that technical validation alone is not sufficient to ensure patient safety. While many open ventilator projects now exist and have gathered impressive numbers of volunteers, there remains a significant global challenge to enable such projects to be regulated appropriately, either in the current crisis or longer-term. The existing system of medical device regulation is slow, expensive, and conservative; while this conservatism has its roots in the entirely reasonable desire to prevent harm to patients, the way the system is implemented makes it extremely difficult to certify a medical device without the resources of a large company. Reform of these regulatory systems could enable a more agile approach to the design and manufacture of safety-critical components, but a satisfactory supply chain will also require significantly more quality management than is present in a typical "maker space" run by volunteers, hobbyists, or even experienced engineers. Questions around training and liability are also of paramount importance; while litigation against volunteers acting in good faith seems unduly harsh, there must be accountability in the supply chain of medical devices. Otherwise, we push responsibility onto the clinical staff using uncertified equipment, which adds a crippling burden to front-line staff who are already working at the limit of their capacity.

Overall, I think it's right to keep an optimistic tone, while acknowledging the obvious difficulties associated with the current challenge. It's likely that, while there are many 3D printers available around the world, formal structures that do not yet exist will be needed to enable them to be fully employed to solve supply issues in this and future crises. Whether or not it is possible to make use of community designed and built ventilators in the coming months, I look forward to a world where critical supplies can be designed and produced openly for the common good. If we take the opportunity to put LMICs on a more equitable footing with respect to richer nations, the future may be more inclusive, as well as more resilient.

\section{Is the topic of the review discussed comprehensively in the context of the current literature?}

Yes

Are all factual statements correct and adequately supported by citations? Yes 


\section{Is the review written in accessible language?}

Yes

Are the conclusions drawn appropriate in the context of the current research literature? Yes

Competing Interests: No competing interests were disclosed.

Reviewer Expertise: Automated microscopy and open source hardware

I confirm that I have read this submission and believe that I have an appropriate level of expertise to confirm that it is of an acceptable scientific standard.

Author Response 28 Apr 2020

Joshua M. Pearce, Michigan Technological University, Houghton, USA

Thank you for the thorough review and kind comments. I agree with you that the state of full open source disclosure in the general literature is disappointing and share your hope that the current move towards open science continues to accelerate.

In this revised version I attempted to pull the grey literature review up to date, but as you point out that is a daily battle and I have cited the work by Read et al., trying to do that on Github.

I share your surprise in the wave of what can only be described as "open washing" where high profile organizations announce their development of an open source ventilator, which upon closer inspection is not open and/or not all of the critical files have been shared. To address this, I have greatly expanded the introductory information and definition of openness as well as provided a few examples.

I have also offered additional thoughts on "when to share" in the Future Work Needed Section.

After considering your points and those of the other reviewers about the advantages of less developed regulatory systems I have simply removed this entirely.

Competing Interests: None

\section{Comments on this article}

\section{Version 1}


Manfred Niehus, isel/it, Lisboa, Portugal

Good review, Thank you. Please re-check the updated Ref 29 and consider to soften the claim in the article accordingly. stay safe!

Competing Interests: No competing interests were disclosed.

Reader Comment 31 Mar 2020

Santhosh Kumar Rajamani, Banas medical college and research institute, India

Even the ventilation protocols used in Ventilators is a proprietary and patented. This leads to confusion and patient injuries notably under ventilation, pneumothorax. Even the ventilation strategy has to be Open sourced. Great idea and best of luck!

Competing Interests: None

The benefits of publishing with F1000Research:

- Your article is published within days, with no editorial bias

- You can publish traditional articles, null/negative results, case reports, data notes and more

- The peer review process is transparent and collaborative

- Your article is indexed in PubMed after passing peer review

- Dedicated customer support at every stage

For pre-submission enquiries, contact research@f1000.com 